\title{
Jovens rurais e influências institucionais para a permanência no campo: um estudo de caso em uma cooperativa agropecuária do Triângulo Mineiro*
}

\author{
Rural youth and institutional influences to stay in the field: a case study in an \\ agricultural cooperative belonged to Triângulo Mineiro

\section{La jeunesse rurale et les influences institutionnelles de rester dans le domaine: une étude de cas dans une cooperative agricole du Triângulo Mineiro}

\author{
Amábile Tolio Boessio** \\ (amabiletolio@hotmail.com) \\ Sheila Maria Doula*** \\ (sheiladoula@gmail.com)
}

Jóvenes rurales e influencias institucionales para la permanencia en el campo: un

estudio de caso en una cooperativa agropecuária del Triângulo Mineiro

Recebido em 10/11/2015; revisado e aprovado em 26/11/2015; aceito em 30/03/2016

DOI: http:/ / dx.doi.org/10.20435/1984-042X-2016-v.17-n.3(02)

\begin{abstract}
Resumo: Objetivou-se investigar a percepção dos jovens rurais filhos de famílias associadas da Cooperativa Agropecuária de Patrocínio (COOPA/MG) sobre o incentivo das instituições (cooperativa e família) para sua permanência no meio rural e na atividade agropecuária, em um estudo de caso com cunho qualitativo do tipo exploratório. Os jovens têm interesse em permanecer no rural e na atividade familiar. Comparando com o estímulo da família, o estímulo da cooperativa é menor.
\end{abstract}

Palavras-chave: juventude rural; reprodução social; instituições sociais.

Abstract: This study aimed to investigate the perception of rural young children of families associated to Patrocínio's Agricultural Cooperative (COOPA/MG) on encouraging institutions (cooperative and family) for their stay in the countryside and agricultural activity, in a case study with qualitative and exploratory nature. Young people are interested in staying in rural and family activity. Compared to the family stimulus, the stimulation of cooperative is less.

Key words: rural youth; social reproduction; social institutions.

Résumé: Cette étude a visé à étudier la perception des jeunes enfants dans les zones rurale de familles associés de la Coopérative Agricole de Patrocínio (COOPA/MG) à encourager les institutions (coopératives et de la famille) pour leur séjour dans la campagne et l'activité agricole, dans une étude de cas avec la nature qualitative et exploratoire. Les jeunes sont intéressés à rester dans l'activité rurale et familier. Par rapport à la relance de la famille, le stimulus de la coopérative est moins intéressant.

Mots-clés: jeunes ruraux; reproduction sociale; institutions sociales.

Resumen: Este estudio tiene como objetivo investigar la percepción de los jóvenes rurales hijos de familias asociadas a la Cooperativa Agropecuária de Patrocínio (COOPA/MG) sobre el incentivo de las instituciones (cooperativa y familia) para su permanencia en el medio rural y en la actividad agropecuaria, en un estudio de caso de naturaleza cualitativa y tipo exploratorio. Los jóvenes se interesan en permanecer en el medio rural y en la actividad familiar. En comparación con el estímulo de la familia, el estímulo de la cooperativa es menor.

Palabras clave: juventud rural; reproducción social; instituciones sociales.

\footnotetext{
* Este artigo é oriundo da dissertação de mestrado da primeira autora sob orientação da segunda autora. A dissertação foi defendida em 2015, no Programa de Pós-graduação em Extensão Rural da Universidade Federal de Viçosa (UFV/MG). A pesquisa teve apoio financeiro do Convênio do Observatório Mineiro do Cooperativismo, junto com a Secretaria de Estado de Desenvolvimento Econômico de Minas Gerais (SEDE) e do CNPq.

** Universidade Federal de Santa Maria (UFSM), Santa Maria, Rio Grande do Sul, Brasil.

*** Universidade Federal de Viçosa (UFV), Viçosa, Minas Gerais, Brasil.
} 


\section{INTRODUÇÃO}

O processo de colonização ao qual o Brasil foi submetido, o legado de conflitos relativos às disputas de terras e a forma como foi aplicada e difundida a tecnologia no campo acarretaram uma visão simplista e discriminatória que grande parte da população ainda carrega e absorve em relação ao espaço rural. Atualmente, porém, com a intensificação das transformações sociais provocadas pela modernização e urbanização do campo, verifica-se um processo de "recomposição do rural", fazendo emergir uma nova ruralidade em seus modos contemporâneos de reestruturação (WANDERLEY, 2009).

Favareto (2007) aponta o início desse novo momento, no qual os espaços rurais estão cada vez mais integrados a novas e complexas dinâmicas. Surgem, nesse contexto, novos agentes e interesses, novas estruturas de oposições e identidades. Diante dos diversos recortes da realidade do meio rural e percebendo as significativas transformações ocorridas nesse meio, torna-se importante compreender que os jovens, como novos atores sociais, são fundamentais no processo de desenvolvimento dos espaços rurais contemporâneos.

A preocupação com a permanência juvenil no campo e também na agricultura familiar é instigada pelo significativo êxodo rural, que vem resultando em uma tendência ao envelhecimento e masculinização no campo. Esse processo se torna tema presente na agenda de pesquisas do país a partir da década de 1980.

Nesse sentido, Brumer (2006) considera que dois aspectos são recorrentes na sociologia rural brasileira e ainda tratados como problemas não resolvidos, que se configuram como entraves para a reprodução social no campo e para os programas de desenvolvimento rural: a continuidade da tendência emigratória de jovens decepcionados com a atividade agrícola e que não querem repetir a trajetória de seus pais e os problemas da exclusão de parte dos filhos no processo sucessório dos estabelecimentos agrícolas familiares.

Brumer (2014) indica que as pesquisas que abordam o segmento juvenil tinham como foco central de análise as principais causas de desinteresse dos jovens em permanecer nas atividades agrícolas ou o fascínio pelas cidades. A autora salienta que é recorrente na literatura sobre a juventude rural a preocupação quanto à definição dos aspectos estruturais que determinam qual o papel e o lugar da juventude e que, por sua vez, restringem a liberdade de escolhas. Dessa forma, observar pelo ângulo econômico os motivos que levam à permanência ou não do jovem no campo é fundamental na medida em que limitações econômicas ainda persistem.

Segundo Brumer (2014), para o segmento juvenil, são fatores motivadores para a saída do campo as más condições de trabalho vinculadas às incertezas de rentabilidade. Em concordância, Silvestro et al. (2001) apontam que muitos filhos de produtores rurais abandonam os negócios familiares por melhores oportunidades de renda fora do meio rural, pois comparativamente as atividades ligadas ao campo são consideradas pouco atrativas quanto aos rendimentos.

Partindo-se do pressuposto de que as diversas instituições presentes no meio rural são fundamentais no processo de formação de opinião do segmento juvenil e na transformação de sua realidade, nesta pesquisa foram investigadas as influências diretas de duas instituições, uma cooperativa agropecuária e as famílias dos jovens rurais. Objetiva-se, neste artigo, analisar a percepção dos jovens rurais filhos de famílias associadas da Cooperativa Agropecuária de Patrocínio (COOPA), em Minas Gerais, sobre o incentivo de ambas as instituições quanto à permanência juvenil no meio rural e na atividade agropecuária. 


\section{JUVENTUDE RURAL E REPRODUÇÃO SOCIAL NO CAMPO}

A categoria juventude, segundo Stropasolas (2006, p. 180), "unifica simbolicamente um grupo que é composto diversamente, que encobre realidades socialmente diversificadas". O autor destaca que, embora existam dificuldades no que tange à conceituação de juventude, esta é uma porta para que se possa construí-la, especialmente no caso específico da juventude rural, pois "inúmeros agentes e instituições externos, que pensam ou representam as políticas e as intervenções no espaço rural, o fazem desconsiderando ou não problematizando a heterogeneidade presente entre seus membros" (STROPASOLAS, 2006, p. 176).

Carneiro e Castro (2007) compreendem a juventude rural em sua dupla dinâmica social. Por um lado, a dinâmica territorial que relaciona a casa (a família), a vizinhança (a comunidade local) e a cidade (o mundo urbano-industrial) e, por outro lado, a dinâmica temporal, relacionada ao passado das tradições familiares, que inspira práticas e estratégias no presente e no encaminhamento do futuro. De acordo com Carneiro e Castro (2007, p. 24), "mais do que espaços distintos e sobrepostos, trata-se essencialmente dos espaços de vida que se entrelaçam e que dão conteúdo à experiência dos jovens rurais e à sua inserção na sociedade".

Paulo (2011) também considera que não se pode definir o jovem apenas de forma objetiva, mas sim dentro de um conjunto das subjetividades e que há a necessidade de entender esse segmento por meio da concepção de uma construção sociocultural ligada a um processo histórico. Com isso, a autora enfatiza a necessidade de entender o meio rural como um espaço de vida e as relações que os jovens vivenciam, uma vez que, somente por meio do conjunto dessas relações, com a família e com o mundo, e junto com a percepção que o próprio jovem tem dele mesmo, é que será possível entender as identidades desses atores sociais.

De acordo com Castro et al. (2009), o papel social atribuído aos jovens rurais entre os anos 1990 e 2000 focalizava a importância desse segmento para o futuro da agricultura familiar, em razão da preocupação com as condições de reprodução social no campo e com a continuidade das atividades agropecuárias voltadas à produção de alimentos. Stropasolas (2006, p. 173) considera, no entanto, que
[...] os jovens reclamam por mu- danças na condição social dos agricultores na sociedade e nos valores que fundamentam as relações de gênero e geração na agricultura familiar; todavia, por não encontrarem espaço para as transformações, mudam-se para a cidade.

O autor conclui que os jovens, embora busquem "mudar de vida" procurando melhores condições nas cidades, "também mantêm uma forte identidade cultural com um ethos [...] expresso na procura regular, nos finais de semana, pela sociabilidade das comunidades rurais" (STROPASOLAS, 2006, p. 173).

Ao realizar uma pesquisa em dois contextos rurais diferentes, Carneiro (1999) percebeu que os jovens, por mais que almejem um padrão de vida melhor e interligado ao estilo moderno e urbano, também demonstram um sentimento de compromisso com a família e com o local, sendo essa uma das contradições presentes no desejo de ter "o melhor dos dois mundos" (ABRAMOVAY et al., 2007). Estes autores, ao realizarem uma pesquisa no oeste de Santa Catarina, constataram que há por parte de rapazes pretensão em continuar nas atividades agrícolas já desenvolvidas por seus pais; os jovens, no entanto, enfatizaram a precariedade dessas propriedades devida, em grande parte, à falta de apoio e de organização das instituições locais que representam os agricultores. Esse quadro, na perspec- 
tiva dos pesquisadores, não é verificado apenas ali, o que mostra que a construção de espaços para participação e representação desses atores ainda é fundamental no meio rural.

Carneiro e Castro (2007) apontam que atualmente os jovens estão percebendo, de uma forma mais positiva, o meio rural, valorizando-o como tranquilo, seguro e com boa qualidade de vida, contrariando o que antes era percebido pela sociedade como atrasado e parado. Em concordância, como colocam Doula et al. (2014) a partir da pesquisa com jovens rurais da Zona da Mata Mineira, os jovens estão valorizando como fatores positivos do rural a tranquilidade, a segurança, ser dono da propriedade e também a liberdade, entendida como a ausência de certos controles que o trabalho nas cidades impõe (horários rígidos, a vigilância do patrão, dentre outros).

Conforme aponta Redin (2012), a valorização positiva ou negativa do rural pelos jovens envolve as condições materiais, os espaços de sociabilidade, bem como a oportunidade de continuar os estudos sem necessitar migrar. Para o autor, ampliar o campo de possibilidades para a concretização desses anseios é fundamental e deve ser um elo para gerar melhor patamar de qualidade de vida e para assegurar a realização dos projetos alternativos individuais e coletivos.

Brumer e Spanevello (2008), ao se referirem à continuidade da agricultura familiar e das unidades produtivas, consideram que os fatores que facilitam ou dificultam a permanência dos jovens no campo, além de não serem únicos, não são isolados. Esses fatores estão atrelados às condições socioeconômicas da família e da propriedade, à educação, ao acesso ao lazer, ao envolvimento e participação em movimentos sociais, à remuneração e autonomia juvenil, à perspectiva de herdar a propriedade e suceder os pais, à percepção acerca do trabalho agrícola, à facilidade de acesso ao crédito e às polí- ticas públicas, em especial as de auxílio à juventude, entre outros.

Por fim, Stropasolas (2011) considera importante, no esforço analítico sobre a juventude rural, situar as constantes modificações exigidas pelas complexidades do mercado que tornam delicadas não só as decisões de mudança na gestão econômica das propriedades, mas também a transferência patrimonial familiar com a substituição, nem sempre harmoniosa, das gerações mais antigas. Em concordância, Redin (2014) entende a importância de se debater acerca de intervenções institucionais que tenham como objetivo elaborar estratégias de reprodução tanto social quanto econômica no campo, além da necessária valorização da profissão de agricultor. Se as gerações futuras refutarem os trabalhos ligados ao campo como simbolicamente depreciativos, todos os processos mencionados não serão eficazes. Por isso torna-se relevante entender as motivações juvenis e sua relação com as instituições presentes no meio rural.

\section{AS INSTITUIÇÕES "COOPERATIVA" E "FAMÍlIA"}

No clássico "As regras do método sociológico", Durkheim (2001), ao definir a sociologia como a ciência das instituições, conceitua instituição como todos os modos, comportamentos e crenças instituídas pela coletividade. Para o autor, a existência das instituições orienta o desenvolvimento social e, para que a sociedade tenha um bom funcionamento, é necessária a harmonia entre as instituições que a constituem, afinal estas são as que regem as normas, condutas, valores morais que passam a fazer parte de uma consciência coletiva.

Para Berger e Berger (1994), a historicidade é relevante para o entendimento da necessidade de se constituir uma instituição, pois existem instituições para a vida coletiva/social, como por exemplo, o 
Estado e instituições para a vida privada, como por exemplo, a família. Os autores destacam que cada instituição é responsável por um ou mais valor social.

Souza (2013) considera instituições sociais tudo o que for indispensável ao funcionamento da sociedade, sendo por meio dessa organização que os indivíduos se inserem no mundo da linguagem, da cultura e da produção. Para a autora, o fato de as instituições sociais ocidentais atualmente terem suas bases fundamentalmente mantidas pelo predomínio da lógica capitalista, faz com que seja necessária a existência de complexas instituições formadoras dos sujeitos sociais, mas elas nem sempre estão em equilíbrio, ao contrário do que havia proposto Durkheim.

Para os interesses deste artigo, importa entender conceitualmente as organizações cooperativas como instituições sociais. De acordo com Valadares (1999, p. 17), “a organização cooperativa é um sistema impulsionado por metas individuais, metas organizacionais e metas do marco institucional da sociedade em geral". No entendimento de Schmidt e Perius (2003, p. 63), "as cooperativas são associações autônomas de pessoas que se unem voluntariamente e constituem uma empresa, de propriedade comum, para satisfazer aspirações econômicas, sociais e culturais".

Segundo a Food and Agriculture Organization (FAO), as cooperativas estão presentes em países desenvolvidos e em desenvolvimento e, mundialmente, abarcam cerca de um bilhão de membros, em grande parte provenientes do setor agroalimentar. A importância das cooperativas agroalimentares foi particularmente reconhecida em 2012, quando a organização instituiu o Ano Internacional das Cooperativas. No âmbito dessa comemoração, a organização considera que “agricultural cooperatives play an important role in supporting small agricultural producers and marginalized groups such as young people and women"1 (FAO, 2012). Inserindo a juventude como agenda prioritária, a FAO elaborou um mapeamento das cooperativas que trabalham com e para os jovens, identificando no Brasil a Cooperativa Agropecuária Regional de Palmeira dos Índios Ltda. (CARPIL), no estado de Alagoas.

A FAO define que seja papel das cooperativas agroalimentares a intermediação e promoção dos interesses gerais da sociedade, como a segurança alimentar, o combate à fome e à pobreza, a geração de empregos no campo e o desenvolvimento rural sustentável. Especificamente em relação aos membros agricultores, sua importância na esfera produtiva reside na oferta de serviços, incluindo o acesso a mercados, recursos naturais, informação, comunicação, tecnologias, crédito, formação e capacitação, preços mais baixos para insumos agrícolas (como sementes, fertilizantes e equipamentos) e condições de armazenamento. Na esfera política, as cooperativas devem facilitar a participação dos pequenos produtores na tomada de decisões em todos os níveis, apoiá-los na obtenção de direitos de uso da terra e negociar melhores condições em contratos agrícolas e preços nos mercados locais, nacionais e internacionais " (FAO, 2012).

Como exposto por Presno Amodeo (1999), nos valores sociais que fundamentam as cooperativas, fica evidente o compromisso que essas organizações assumem com seus cooperados e também com a coletividade onde estas se desenvolvem. Para a autora, dois princípios recebem destaque: Educação, formação e informação e Preocupação com a Comunidade. Nessa mesma linha, como exposto por Freitas e Freitas (2013), em pesquisa realizada em uma cooperativa

\footnotetext{
1 “Cooperativas agrícolas desempenham papel importante no apoio a pequenos produtores agrícolas e a grupos marginalizados, como de jovens e mulheres" (tradução da revisora).
} 
de crédito solidário na Zona da Mata de Minas Gerais, a importância dessas organizações coletivas está na educação e na conscientização econômica, em especial dos agricultores familiares, o que auxilia no desenvolvimento local pela via da promoção da cooperação.

Ao considerar a existência de uma cooperativa em virtude de seus associados e a inclusão da família e da comunidade como foco de sua ação institucional, cabe também indicar as características da instituição família para as análises aqui apresentadas. Família, por sua complexidade, é um termo de difícil definição, em especial nos tempos atuais; o seu entendimento varia segundo fatores como contexto, cultura, relações, crenças, entre outras peculiaridades dos grupos.

Prado (1988) apresenta o sentido popular e ainda dos dicionários, nos quais família significa um conjunto de pessoas aparentadas, geralmente pai, mãe e filhos, que vivem em uma mesma residência. Já para Donati (2008, p. 51), “a família é um grupo social humano primário, mas não um grupo qualquer [...] a família é aquele "sistema social vivente" que preside a reprodução primária da sociedade".

No contexto rural, Loreto (1996) considera que a família, em especial aquela vinculada à pequena produção, é caracterizada por ser, ao mesmo tempo, produtora e consumidora. Para a autora, é na família que as atividades a serem desenvolvidas são organizadas e distribuídas, bem como a família constitui-se como local de tomadas de decisão, o centro onde são desenhadas as regras e conduzidos os modos de se viver.

Na perspectiva da historicidade que é própria das instituições, como apontaram Berger e Berger (1994), algumas modificações recentes na configuração das relações de poder podem ser observadas na esfera familiar, embora seus resultados ainda não permitam um consenso. Silvestro et al. (2001) defendem, a partir de pesquisa realizada em Santa Catarina, que atualmente há o enfraquecimento do poder quase absoluto da figura paterna dentro da organização familiar tradicional rural. Essa mudança estaria abrindo espaço para a formação de um ambiente com maior participação de todos os membros da família, resultando em uma configuração mais "democrática". Contrariando essa perspectiva, Stropasolas (2011), com base em pesquisas também realizadas em Santa Catarina, considera que, além dos conflitos gerados pelos diferentes interesses dentro do grupo familiar, um grande gerador de conflitos é o modelo de gestão centralizado no pai e a grande dificuldade deste em aceitar inovações, geralmente propostas pelos filhos, nos processos gerenciais.

Ainda nesse sentido, Spanevello et al. (2011), em pesquisa realizada na região central do Rio Grande do Sul, constataram que são variados os fatores que fazem com que os jovens decidam por não seguir na atividade que até então vem sendo desenvolvida pela família, dentre os quais as tarefas penosas próprias do trabalho rural, a falta de abertura dos pais para diálogo e a busca de autonomia financeira. Essas observações são importantes porque denotam contextos sociais em transformação, o que coloca desafios adicionais para as várias outras instituições que atuam no meio rural.

\section{METODOLOGIA E CARACTERIZA- ÇÃO DO UNIVERSO EMPÍRICO}

O presente artigo apoia-se em uma metodologia de cunho qualitativo do tipo exploratória, desenvolvida em um estudo de caso. Para a realização da pesquisa de campo, foi utilizada como ferramenta de coleta de dados a entrevista, conduzida por um roteiro diferenciado segundo as características dos grupos de atores sociais: 41 entrevistas com famílias cooperadas, 13 entrevistas com membros da direção, cargos de gestão e colaboradores da Cooperativa e 22 entrevistas com 
jovens, filhos de cooperados, de ambos os sexos e com idade entre 18 e 29 anos. Posto que o objetivo deste artigo é analisar a percepção dos jovens sobre o incentivo de duas instituições (cooperativa e família) para sua permanência no meio rural, o foco analítico incide nas entrevistas com o segmento juvenil.

As entrevistas foram realizadas nas propriedades familiares por meio das visitas técnicas junto com extensionistas e em reuniões de comunidade realizadas pela Cooperativa Agropecuária de Patrocínio (COOPA). A escolha da COOPA para a investigação é justificada pelo destaque que ela vem obtendo no Movimento Cooperativista Mineiro, principalmente pela organização do quadro de associados e sua preocupação com os jovens interligados a ela. Além das Comunidades Cooperativistas, a COOPA conta com um Núcleo de Mulheres e o Núcleo de Jovens Cooperativistas.

A pesquisa foi desenvolvida na mesorregião do Triângulo Mineiro/Rio Paranaíba. O Estado de Minas Gerais, de acordo com dados do IBGE (2010), é composto por 12 mesorregiões e 66 microrregiões. A mesorregião do Triângulo Mineiro/ Alto Paranaíba abarca sete microrregiões, dentre elas a de Patrocínio, onde se localiza o município com o mesmo nome.

Caracteristicamente uma região agrícola, o Triângulo Mineiro/Alto Paranaíba, desde os anos 1970, vem se modernizando por meio de intensos investimentos governamentais. Economicamente, a região vem tendo destaque tanto no que tange a seu complexo agroindustrial de processador de grãos e carne como pela constante modernização na pecuária extensiva. Esta é uma das regiões do país que melhor se adaptou ao novo padrão agrícola (BRANDÃO, 1989). De acordo com Schuls, Gatti Junior e Silva (2000, s.p.), “a região do Triângulo Mineiro/Alto Paranaíba é um centro de referência econômica e cultural para o Centro-Oeste e se constitui em polo de confluência de diferentes demandas científicas e culturais".

O município da sede administrativa da COOPA possui uma população total de 82.471 habitantes, sendo que grande parte é composta pela faixa etária entre 5 a 49 anos, havendo equilíbrio entre homens e mulheres.

Para melhor caracterização do contexto no qual os jovens entrevistados se inserem, destaca-se que, na área da educação de nível fundamental e médio, Patrocínio conta com 12 escolas na rede municipal, 21 escolas da rede estadual e ainda quatro escolas particulares (PATROCÍNIO, s.d.). Na educação de nível técnico e superior, de acordo com o Ministério da Educação (BRASIL, s.d.), no município há cinco Instituições de Ensino Superior (IES), sendo elas: Centro Universitário de Maringá (Unicesumar), Faculdade de Patrocínio (IESP), Instituto Federal de Educação, Ciência e Tecnologia do Triângulo Mineiro, Universidade Paulista (UNIP) e o Centro Universitário do Cerrado (UNICERP); o município conta ainda com a Escola Agrotécnica Sérgio de Freitas Pacheco (EASFP) e a Fazenda Experimental (FUNCEP).

OUNICERP oferece cursos de graduação como Administração, Agronegócio, Agronomia, Cafeicultura, Ciências Contábeis, entre outros e ainda cursos de Pós-graduação. A EASFP oferece o curso Técnico em Agropecuária em modalidades Concomitante e Subsequente. A Fazenda Experimental FUNCEP tem o intuito de dar suporte aos cursos do UNICERP, em especial aos cursos de Agronomia e Agronegócio; conta com estruturas para as criações de gado, porco e granja de aves, para os cultivos e novas tecnologias para a produção de banana, café, milho, soja, maracujá, entre outros e, ainda, parcerias com empresas ligadas à pecuária leiteira.

A oferta de ensino superior no município, bem como na região, possibilita que os jovens tenham maior acesso à formação 
e capacitação, o que por sua vez oportuniza a inserção dos jovens no mercado de trabalho com melhor qualificação. No Instituto Federal presente no município são oferecidos os cursos técnicos em informática, eletrônica e contabilidade e ainda o Curso Superior em Análise e Desenvolvimento de Sistemas. Para o presente estudo observa-se também a oferta dos cursos superiores de Administração e Agronegócios na Faculdade de Patrocínio (IESP).

O município de Patrocínio, de acordo com dados do último CENSO agropecuário, apresenta o $3^{\circ}$ maior PIB agropecuário da mesorregião do Triângulo Mineiro/Alto Paranaíba. Do total de municípios da microrregião de Patrocínio (11 municípios), sete são pertencentes à área de atuação da COOPA. A cooperativa foi fundada em 1961 e atualmente conta com 2.898 cooperados. A produção de leite é o foco da cooperativa, embora ela também inclua em seus negócios a produção de café, utilizado para troca em seus estabelecimentos comerciais.

\section{AS PERCEPÇÕES JUVENIS SOBRE O INCENTIVO DAS INSTITUIÇÕES}

Dos 22 jovens entrevistados, a maioria $(63,63 \%)$ tem idades que variam entre 18 e 24 anos. Quanto ao estado civil, 86,36\% são solteiros, sendo apenas dois casados e um em união estável. Em relação ao gênero, a minoria $(27,27 \%)$ dos jovens é do sexo feminino. Não se pode afirmar que o fato de a maioria dos entrevistados serem homens signifique uma tendência à masculinização rural, porque, além de a amostra ser reduzida considerando a totalidade de jovens da região, o estado de Minas Gerais e a cidade de Patrocínio não demonstram tal característica.

Quanto ao local onde residem, $72,73 \%$ dos jovens moram nas propriedades familiares, sendo que os demais residem na cidade, pois, em grande parte, trabalham como técnicos de campo e conciliam tal função com as atividades na unidade produtiva. Ao considerar o tempo de moradia, os respondentes que residem no meio rural desde que nasceram totalizam 15 , sendo apenas um residente há 3 anos - desde que assumiu os negócios familiares. Já aqueles que estão morando na cidade, apenas um nunca morou no campo - esse caso específico corresponde a um jovem que residiu 10 anos fora do país e retornou para assumir a propriedade da família, porém apenas vincula a propriedade à atividade e não como local de moradia.

Dos jovens rurais participantes da pesquisa, apenas três já são associados da COOPA, os demais justificaram a não associação por conseguirem realizar tudo no nome do pai e demonstraram interesse em se associar futuramente. Quanto ao trabalho, todos se declararam trabalhadores rurais. Aqueles que trabalham somente na propriedade familiar totalizam 15 jovens, e um jovem, além de trabalhar na propriedade familiar, ainda é contratado como tratorista em uma propriedade vizinha; seis filhos de cooperados trabalham na COOPA como técnicos de campo ou nas lojas agrícolas.

Os jovens pesquisados, em sua maioria $(77,27 \%)$, não estão mais estudando, porém isso se justifica por já terem concluído o curso superior e estarem trabalhando na área de formação. Dez jovens possuem formação na área das atividades desenvolvidas nas propriedades e, destes, nove possuem ensino superior; cinco são formados em áreas administrativas e uma jovem possui pós-graduação. Dos jovens que estão estudando atualmente (cinco), quatro estão cursando agronomia (um deles já é técnico agrícola), e uma jovem iniciou o curso de engenharia civil.

Ao tratar das percepções desses jovens sobre os estímulos que recebem tanto da cooperativa quanto de suas famílias para a permanência na propriedade familiar e, ainda, na atividade já desenvolvida por seus pais, quase a totalidade dos en- 
trevistados, como observado no Quadro 1, respondeu de forma positiva em relação à família. Já quando questionados a respeito do mesmo incentivo por parte da COOPA, o número de respostas positivas foi menor, mas também expressivo.

\begin{tabular}{|c|c|}
\hline $\begin{array}{c}\text { INCENTIVO PARA A PERMANÊNCIA DO JOVEM NO CAMPO/ } \\
\text { ATIVIDADE AGROPECUÁRIA }\end{array}$ & $\%$ \\
\hline DA FAMÍLIA & 90,90 \\
\hline DA COOPA & 68,18 \\
\hline
\end{tabular}

Quadro 1 - Incentivo da família e da cooperativa para a permanência no campo e na atividade agropecuária, jovens filhos de cooperados, COOPA.

Fonte: Pesquisa de campo, 2015.

De forma geral, os jovens percebem incentivo da cooperativa, em especial pela presença dos técnicos de campo nas propriedades, mas o estímulo familiar é vinculado à tradição e torna-se mais significativo, conforme mostram os depoimentos:

Meu pai nasceu aqui na fazenda né, o meu vô tinha as terras aí pegou e passou pra eles, aí tinham 5 hectares de café, ele pegou e plantou, mas o sonho dele era planta 15 hectares, 5 pra cada filho. Aí ele plantou esses 5 e vinha cuidar e foi mexendo com leite. E a cada ano começou a plantar mais um pouquinho, mais um pouquinho e tá com 120 hoje. Aí a gente foi vendo que o negócio tava crescendo demais e deixar na mão de funcionário não dava certo e foi a experiência que nós tivemos aqui, aí largou de mexer com leite porque deixando nas mãos dos funcionário tavam acabando com tudo que tinha. Aí eu resolvi largar o escritório de contabilidade que a gente tinha lá e trabalhava lá pra vim toma conta e trabalha aqui na roça. (JOVEM 10²).

Eles incentivam de mais de nós fica. Se fosse pelo meu pai eu tava mais lá plantando uma lavoura a mais de café. (JOVEM 14).

\footnotetext{
${ }^{2}$ Para manter o anonimato dos jovens, optou-se pela atribuição numérica dos entrevistados.
}

Em relação ao incentivo por parte da COOPA, foram selecionados trechos de entrevistas que demonstram o papel de formação e informação atribuído a essa instituição e que contribuem nas atividades desenvolvidas nas unidades de produção:

Ajuda muito né. Se não fosse pela Cooperativa acho que não fazia esses cursos não né. Aqui é fácil, vem prá comunidade aqui, é tudo pertinho de casa né, agora se nóis tivé que sair daqui pra ir pra cidade aí já acho que é mais difícil né. (JOVEM 1).

Ah, incentiva sim, por exemplo, quando eu fiz técnico, a cooperativa que me deu a bolsa de estudos pra fazer, eu acho que isso já é um tipo de incentivo que ela dá. (JOVEM 13).

A cooperativa ajuda sim, estimula. Igual, tendo assistência técnica, trabalhando direitinho e vendo que dá lucro que tem rentabilidade incentiva muito. (JOVEM 14).

Assim, esse negócio de permanência depende muito de incentivo familiar, mas a COOPA tem vários instrumentos dentro dela que ajudam a ter um norte, tem muito treinamento, bastante palestra, que eu acho que estimula o jovem, o adolescente a querer ficar na área rural. Porque daí a criança começa a participar das 
reuniões, adolescentes, aí vai gostando daquela atividade né, eu acho que isso tendência a querer permanecer. (JOVEM 17).

Os jovens entrevistados foram questionados também sobre o que a COOPA ainda poderia fazer para incentivar os jovens a permanecerem nas atividades já desenvolvidas pelos núcleos familiares. As respostas indicam uma demanda por novas tecnologias que resultem em maior eficiência e, consequentemente, em maior rentabilidade:

Acho que o que mais tá faltando agora é curso mesmo, que nem, vai numa reunião é um assunto, trata dele mas aí depois vai na outra reunião e fala de outra coisa. Se eu quero agora fazer um curso de inseminação, não tem. Aprimorar as técnicas sempre ajuda o jovem a querer ficar. (JOVEM 9).

Tem que incentivar a pessoa a enxergar a fazenda com um lugar diferente pra viver, porque quem vive lá não é mais bobo, nada disso. Tem que enxergar ela como uma empresa rural, até expandir mais os negócios, não só leite e café. (JOVEM 12).

A cooperativa já faz, mas tem que intensificar de mostrar pro jovem que é uma atividade rentável, que se fizer direitinho pode ganhar até mais que qualquer outro emprego na cidade. Tem que levar é muito exemplo, mostrar dos jovens que começaram a tocar a mesma atividade do pai, que já tá sendo o sucessor do pai e que tá dando muito certo. Porque nesses caso o filho tá empregando mais tecnologia que o pai e aí tá tendo mais sucesso ainda, isso aí é certo que incentiva o jovem. (JOVEM 16).

Os jovens rurais participantes da pesquisa também foram indagados se na propriedade de sua família já foi decidido quem irá suceder aos pais. Somente quatro jovens indicaram que já atuam nas propriedades como sucessores; os demais afirmaram que nunca conversaram com seus pais sobre esse assunto. No entanto, entre os filhos de cooperados pesquisados, a maioria $(86,36 \%)$ dos jovens gostaria de manter a propriedade e os negócios da família, considerando sua permanência no meio rural. Alguns trechos das entrevistas exemplificam tal posicionamento:

Eu quero continuar aqui, trabalhar prá gente é melhor. Minha família incentiva, por vontade deles eu fico aqui sim. Eu até ia prá cidade, trabalhar na Syngenta, mas aí não deu e eu fiquei. Pelo meu pai e pela minha mãe eu fico aqui, eu que cuido do café, das coisas aqui. (JOVEM 1).

Ah, eu gosto desse meio, eu me sinto nesse meio. Igual, eu faço curso de agronomia porque eu quero continuar, mesmo que não for assim na mesma fazenda, mas eu quero continuar. (JOVEM 3).

O que eu tenho de plano é trabalhar aqui [COOPA] até uma certa idade e dali então ficar só lá na propriedade mesmo. (JOVEM 8).

Eu tô fazendo o que eu gosto, cada dia mais eu aprendo, o que eu aprendi na faculdade eu tô podendo emprega aqui no meio rural, aqui em casa na fazenda. Eu tô colhendo o que eu tô plantando. (JOVEM 9).

Eu tenho vontade de ficar, mas é mais por amor mesmo, porque é uma pequena propriedade. Eu enxergo que tem como ganhar dinheiro mas às vezes acaba que é mais fácil enxergar mais oportunidade na cidade. Mas eu queria mesmo era por uma questão de sucessão. Eu acho que é um pecado não continuar aquilo que o meu pai tem e trabalhou a vida inteira e meu avô também. (JOVEM 12). 
Uai eu gosto da fazenda, gosto do lugar, gosto da atividade. Eu gosto muito de café, minha especialidade dentro da agronomia mais é o café mesmo, então eu tenho vontade de abrir mais lavora assim que der. Eu gosto, é paixão mesmo, mas eu não gosto muito de leite. (JOVEM 14).

Eu tenho interesse em continuar sim, eu acredito que seja uma atividade rentável, atividade tranquila de trabalhar né, apesar de depender muito de clima, ter algum contratempo, mesmo assim você tem resultados bons, por isso que eu sempre invisto lá. (JOVEM 16).

Finalmente, os jovens rurais entrevistados responderam ao questionamento sobre o que falta no meio rural para que o jovem ali permaneça. A falta de tecnologia e ainda, em dois casos, a percepção negativa da profissão de agricultor, esta especificamente ligada à mídia e também à desvalorização por parte do governo, foram respostas que deram certa coesão à opinião dos jovens:

O problema em geral é que a agricultura é vista ainda como uma atividade que denigre a imagem, e isso é cultural, não vai ser só a cooperativa que vai mudar. Enquanto a mídia não exaltar o produtor como um fornecedor de comida, de alimento, enquanto ficar exaltando só montadora de carro e coisa assim, não vai adiantar. É visto ainda como atividade rústica, tosca. (JOVEM 12).

Tá faltando lucratividade, porque ninguém guenta só por paixão. Sem dinheiro, não dá pra fazer nada. Eu acho que principalmente o ganho financeiro, porque se o cara tá ganhando bem ele vai pensar duas vezes antes de ir pra cidade, agora, se tá muito ruim, ele vai procurar outros ganhos. Eu mesmo já procurei, saí da fazenda com 17 anos falando eu não vou mexer com isso aqui mais não. Sai, fui prá cidade, trabalhei e decidi voltar, mas eu sai, porque não tava dando nada. (JOVEM 14).

No meu ponto de vista não tá faltando nada. Que nem o seguinte, oportunidade pra vim tem, porque na fazenda tem serviço demais, no meio rural serviço não falta, de qualquer lado. Mas também aqueles que não tem acesso à tecnologia é mais fácil de ir embora. É que a mecanização ela te dá oportunidade de fazer um serviço melhor, você trabalha mais com a cabeça e menos com o corpo. O tamanho da área não interfere, porque em 10 hectare cabe 10 pessoas trabalhando tranquilamente, porque não é pouco serviço. Mas também vai muito da vontade da pessoa de querer ficar né. Que nem aqui ó, eu conheço vizinho de 30 e poucos anos que não quis ficar porque o pai não dava liberdade, se ele fosse ficar ele não tinha oportunidade de tomar decisão, era do jeito que o pai dele queria, aí ele desanima mais fácil né. (JOVEM 10).

A partir das entrevistas e levando em conta o que se destacou na literatura acerca do tema, evidencia-se que a percepção juvenil sobre o rural é formulada por meio de suas relações dentro da família, das relações na comunidade e com a sociedade mais ampla, e das relações com instituições sociais que fazem parte de seu constructo simbólico. Os jovens da pesquisa percebem o rural como um local tranquilo, demonstram sentimentos de pertença familiar e ligação sentimental com a terra, mas também incluem em seu campo de visão as instituições que atuam como estímulo/desestímulo a seus projetos futuros.

Os jovens almejam tecnologia, conforto, certa estabilidade, qualidade 
de vida, ou seja, desejam um rural onde possam construir suas vidas com acesso a tudo o que podem ter em qualquer lugar. Nesse sentido, por mais que a família os incentive para que permaneçam nas unidades produtivas, se as instituições presentes no meio rural não oportunizarem esses acessos, os jovens poderão optar por sair do meio rural. Nota-se que as demandas juvenis por cursos de capacitação/ atualização, possibilidades de expansão e diversificação dos negócios e tecnologias que amenizem o trabalho pesado e permitam maior lucratividade estão contempladas, ao menos teoricamente, nas diretrizes que orientam a atuação e o papel das cooperativas no meio rural.

\section{CONSIDERAÇÕES FINAIS}

Neste artigo, objetivou-se investigar a percepção dos jovens rurais filhos de famílias associadas da COOPA sobre o incentivo das instituições - cooperativa e família - para sua permanência no meio rural e na atividade agropecuária. Observou-se que, embora haja um percentual maior de respostas em relação ao apoio familiar, na percepção dos jovens, a cooperativa também é vista como instituição incentivadora. Os jovens da pesquisa demonstraram a grande importância em sua escolha de permanência, tanto em função do incentivo familiar, como pelo fato de a cooperativa oferecer condições para melhorias na produção agropecuária. Destaca-se que a maioria $(86,36 \%)$ dos entrevistados pretendem continuar nas propriedades familiares e ainda mantendo a atividade já desempenhada pela família.

Foi perceptível nas entrevistas com os jovens como a instituição cooperativa pode adentrar no auxílio da permanência juvenil e facilitar a reprodução social nas unidades produtivas familiares de seus associados. Para esses jovens, a cooperativa deveria investir em cursos que os capacitem para continuar as atividades dos pais, no sentido de mostrar para a juventude que esta é uma profissão rentável e, quando aliada à tecnologia, torna-se uma profissão menos penosa. Levando em consideração que esses jovens pretendem suceder a seus pais, cabe mencionar que estes, em grande parte, pretendem fazê-lo mudando a atividade produtiva, do leite para o café, por considerarem que tal atividade exige menor esforço físico, podendo ser tecnificada com mais facilidade. Daí decorre a necessidade, em futuro breve, de certa flexibilidade e adaptação institucional por parte das famílias e também da cooperativa quanto a perfil da atividade econômica.

Considerando que as cooperativas têm, em seu princípio básico, atender as necessidades de seus membros, cabe colocar que, mesmo o processo sucessório não sendo de sua responsabilidade, pois é de âmbito doméstico e privado, existem mecanismos que ela pode utilizar para amenizar tais falhas comunicativas em relação às unidades familiares, principalmente nos momentos de reuniões nas comunidades, quando as famílias, e não apenas os cooperados, comparecem. As próprias famílias cooperadas participantes da pesquisa focalizaram esses momentos coletivos como propícios para a abordagem dessa fase de transmissão patrimonial.

Torna-se fundamental dispor do fato de que a cooperativa está inserida em uma região que oferece oportunidade de estudos e capacitação para esses jovens, sem que precisem se deslocar, em alguns casos, nem mesmo de município, fato não comum quando se analisa outros contextos de vivência da juventude rural. Os jovens participantes, quase em sua totalidade, continuam residindo na zona rural e deslocam-se diariamente para a cidade onde realizam seus estudos, o que possibilita vincular a formação com o trabalho na unidade de produção familiar. Nesse aspecto, a COOPA conta com filhos de cooperados com nível de formação superior, o que deveria ser valorizado como trunfo em suas ações futuras. As demandas por 
capacitação, nesse caso, abarcam, na perspectiva dos jovens, temas mais pontuais, o que facilitaria a oferta desse serviço por parte da cooperativa.

Finalmente, observou-se que o segmento juvenil pertencente à amostra desta pesquisa se reconhece como rural, mas expõe um desejo de reconhecimento das profissões ligadas ao campo, ao considerar que a sociedade ainda vê esse espaço como atrasado. Em diversos momentos, os jovens demonstraram um posicionamento positivo em relação à profissão e à continuidade das atividades, considerando que não mais se tem um trabalhador rural "matuto" e rústico, mas sim um trabalhador mais vinculado às tecnologias. Talvez por isso tenha sido ressaltado o papel que a cooperativa deve desempenhar como instituição mediadora no acesso e no avanço tecnológico dos jovens, de suas famílias e da população local, pois, além do maior conforto doméstico e das facilidades nos processos produtivos, a tecnologia contribuiria com a valorização simbólica do espaço e das profissões tradicionalmente rurais.

\section{REFERÊNCIAS}

ABRAMOVAY, Ricardo et al. Agricultura familiar e sucessão profissional: novos desafios. 2007. Disponível em: <http:/ / www.gp.usp. $\mathrm{br} /$ files/denru_sucessao.pdf $>$. Acesso em: 18 fev. 2014

BERGER, Peter; BERGER, Brigitte. O que é uma instituição social? In: FORACCHI, Marialice; MARTINS, José de Souza (Org.). Sociologia e sociedade: leituras de introdução à Sociologia. 21. ed. Rio de Janeiro: LTC, 1994.

BRANDÃO, Carlos Antônio. Triângulo: capital comercial, geopolítica e agroindústria. 1989. Dissertação (Mestrado em Desenvolvimento e Planejamento Regional) - Universidade Federal de Minas Gerais, Belo Horizonte, MG.

BRASIL. Ministério da Educação. Instituições de Educação Superior e Cursos Cadastrados do Estado de Minas Gerais. [s.d.]. Disponível em: <http://emec.mec.gov.br/>. Acesso em: 18 jul. 2014.
BRUMER, Anita. A problemática dos jovens rurais na pós-modernidade. In: VII CONGRESO LATINOAMERICANO DE SOCIOLOGÍA RURAL, 2006, Quito (Equador). Anales ..., 2006.

As perspectivas dos jovens agricultores familiares no início do século XXI. In: RENCK, Arlene; DORIGON, Clovis (Org.). Juventude rural, cultura e mudança social. 1. ed. Chapecó, SC: Unochapecó, 2014. p. 115-138.

BRUMER, Anita; SPANEVELLO, Rosani Marisa. Jovens agricultores da Região Sul do Brasil. Porto Alegre, RS: UFRGS; Chapecó, SC: Fetraf-Sul/CUT, 2008. Relatório de Pesquisa.

CARNEIRO, Maria José. O ideal rurbano: campo e cidade no imaginário de jovens rurais. In: TEIXEIRA DA SILVA, Francisco Carlos et al. (Org.). Mundo rural e política. Rio de Janeiro: Campus, 1999.

CARNEIRO, Maria José; CASTRO, Elisa Guaraná de (Org.). Juventude rural em perspectiva. Rio de Janeiro: Mauad X, 2007.

CASTRO, Elisa Guaraná de Castro et al. Os jovens estão indo embora? Juventude rural e a construção de um ator político. Rio de Janeiro: MAUAD X; Seropédica, RJ: EDUR, 2009.

DONATI, Pierpaolo. Família XXI: abordagem relacional. São Paulo: Paulinas, 2008.

DOULA, Sheila Maria; BOESSIO, Amábile Tolio; PAULA, Debora Brandão; SOUZA, Solange Batista; CARMO, Pollyanna Maria. Jovens que ficam - projetos e concretização da vida profissional da juventude rural da Zona da Mata Mineira. In: SITRE SIMPÓSIO INTERNACIONAL TRABALHO, RELAÇÕES DE TRABALHO, EDUCAÇÃO E IDENTIDADE, 4., 2014, Belo Horizonte. Anais... Belo Horizonte, MG: UFMG, 2014. v. 1, p. 1-18.

DURKHEIM, Émile. As regras do método sociológico. 16. ed.São Paulo: Companhia Editora Nacional, 2001.

FOOD A N D A GRICULT URE ORGANIZATION (FAO). Agricultural cooperatives: paving the way for food security and rural development. 2012. Disponível em: <http://www.fao.org/docrep/016/ap431e/ ap431e.pdf>. Acesso em: 20 fev. 2015. 
FAVARETO, Arilson. Paradigmas do desenvolvimento rural em questão. São Paulo: Iglu/Fapesp, 2007.

FREITAS, Alair Ferreira de; FREITAS, Alan Ferreira de. Interações entre organizações coletivas na promoção do desenvolvimento local. Interações, Campo Grande, MS, v. 14, n. 2. p. 177-188, jul./dez. 2013.

INSTITUTO BRASILEIRO DE GEOGRAFIA E ESTATÍSTICA (IBGE). 2010. Disponível em: <http://www.ibge.gov.br/home/ estatistica/populacao/censo2010/default. shtm>. Acesso em: 10 ago. 2014.

LORETO, Maria das Dores Saraiva de. A economia familiar na pequena produção. In: SIMPÓSIO DE ECONOMIA FAMILIAR: Economia familiar: uma olhada sobre a família nos anos 90,1. Viçosa: UFV, 1996. p. 187-215.

PATROCÍNIO. Site da Prefeitura. [s.d.]. Disponível em: <http://www.patrocinio. mg.gov.br/> . Acesso em: 3 ago. 2014.

PAULO, Maria de Assunção Lima de. Juventude rural: suas construções identitárias. 1. ed. Recife, PE: Editora Universitária UFPE, 2011. 324p.

PRADO, Danda. O que é família. São Paulo: Brasiliense, 1988.

PRESNO AMODEO, Nora Beatriz. As cooperativas agroindustriais e os desafios da competitividade. 1999. Tese (Doutorado em Desenvolvimento, Agricultura e Sociedade) Universidade Federal Rural do Rio de Janeiro, Rio de Janeiro.

REDIN, Ezequiel. O futuro incerto do jovem rural. INTESA, Pombal, PB, v. 8, n. 1, p. 37-43, jan./dez. 2014.

Jovem rural em questão. Revista Sociais e Humanas, Santa Maria, RS, v. 25, n. 01, p. 123-139, jan./jun. 2012.
SCHMIDT, Derli; PERIUS, Vergílio. Cooperativismo e cooperativa. In: CATTANI, Antônio David. A outra economia. Porto Alegre, RS: Veraz, 2003.

SCHULS, Almiro; GATTI JÚNIOR, Décio; SILVA, Jefferson Ildefonso da. As políticas públicas de educação e as instituições de educação superior do Triângulo Mineiro e Alto Paranaíba. In: ANPED. GT: Política e Educação Superior. Anais... Rio de Janeiro, 2000. Disponível em: <http://www.anped11.uerj. br/23/1101p.htm>. Acesso em: 3 ago. 2014.

SILVESTRO, Milton Luiz et al. Os impasses da sucessão hereditária na agricultura familiar. Florianópolis, SC: Epagri; Brasília: Nead, Ministério do Desenvolvimento Agrário, 2001.

SOUZA, Eliete Ramos. A escola como instituição social: revisitando a função social da escola. 2013. Dissertação (Mestrado em Educação) - Universidade Estadual de Londrina, Londrina, PR.

SPANEVELLO, Rosani Marisa et al. A migração juvenil e as implicações sucessórias na agricultura familiar. Revista de Ciências Humanas, Florianópolis, SC, v. 45, n. 2, p. 291304, out. 2011.

STROPASOLAS, Valmir Luiz. O mundo rural no horizonte dos jovens. Florianópolis, SC: Editora da UFSC, 2006.

. Os desafios da sucessão geracional na agricultura familiar. Revista Agriculturas, v. 8, n. 1, p. 26-29, mar. 2011.

VALADARES, José Horta. Cooperativismo rural. Associação Brasileira de Educação Agrícola Superior - Curso de Administração Rural (Módulo 9). Brasília: ABEAS, 1999.69 p.

WANDERLEY, Maria de Nazareth Baudel. $O$ mundo rural como um espaço de vida - reflexões sobre a propriedade da terra, agricultura familiar e ruralidade. Porto Alegre, RS: UFRGS Editora, 2009.

\section{Sobre as autoras:}

Amábile Tolio Boessio: Doutoranda em Extensão Rural na Universidade Federal de Santa Maria (UFSM). Pesquisadora do Observatório da Juventude Rural e do Observatório Mineiro do Cooperativismo. E-mail: amabiletolio@hotmail.com

Sheila Maria Doula: Docente no Departamento de Economia Rural, Pesquisadora do Observatório da Juventude Rural e do Observatório Mineiro do Cooperativismo da Universidade Federal de Viçosa (UFV). E-mail: sheiladoula@gmail.com 